\title{
KESELAMATAN KERJA AKTIVITAS BONGKAR KAPAL BOUKE AMI DI PELABUHAN PERIKANAN NUSANTARA MUARA ANGKE
}

\author{
Occupational Safety of Unloading Activity on Bouke Ami Fishing Vessel at Muara Angke Fishing \\ Port
}

Oleh:

\author{
Erlin Nur Yustikaningsih ${ }^{1}$, Budhi Hascaryo Iskandar ${ }^{1}$, Fis Purwangka ${ }^{1 *}$ \\ ${ }^{1}$ Departemen Pemanfaatan Sumberdaya Perikanan, Fakultas \\ Perikanan dan Ilmu Kelautan, Institut Pertanian Bogor \\ *Korespondensi penulis: fis@psp-ipb.org
}

\begin{abstract}
ABSTRAK
Salah satu lingkup keselamatan kerja pada nelayan yaitu pada aktivitas bongkar hasil tangkapan. Aktivitas bongkar merupakan proses penurunan hasil tangkapan ke dermaga sampai ke Tempat Pelelangan Ikan (TPI). Kegiatan bongkar memiliki potensi kecelakaan kerja paling tinggi, karena pada kegiatan tersebut banyak melibatkan orang dalam aktivitasnya serta terdapat konsekuensi bahaya yang dikategorikan dalam bahaya besar. Tujuan dari penelitian ini yaitu mengidentifikasi aktivitas bongkar kapal bouke ami di PPN Muara Angke, menghitung tingkat risiko aktivitas bongkar anak buah kapal bouke ami, serta memberikan rekomendasi agar keselamatan kerja ABK pada aktivitas bongkar lebih terjamin. Metode dalam penelitian ini adalah observasi dan wawancara kepada nelayan dan ABK mengenai aktivitas kegiatan bongkar dan potensi bahaya yang ada. Analisis yang digunakan berupa analisis deskriptif, analisis Hierarchical Task Analysis, dan metode Job Safety Analysis. Hasil penelitian menunjukkan bahwa terdapat 42 aktivitas pada kegiatan bongkar. Analisis HTA dan JSA menunjukkan dari 42 aktivitas tersebut terdapat 10 (18.18\%) aktivitas yang termasuk kategori ringan, 29 (52.73\%) aktivitas yang termasuk kategori menengah, 9 (16.36\%) aktivitas yang termasuk kategori berat, dan 7 (12.73\%) aktivitas yang termasuk kategori fatal. Terdapat beberapa aktivitas yang mempunyai lebih dari satu kategori. Penerapan pengendalian risiko dapat menurunkan tingkat risiko ke kategori yang lebih rendah. Hal yang perlu diperhatikan yaitu kelengkapan fasilitas berupa life vest terutama pada persiapan operasi serta dibutuhkan pengemudi transportasi hasil tangkapan yang bersertifikat guna mencegah terjadinya kecelakaan yang bersertifikat guna mencegah terjadinya kecelakaan yang bersifat fatal.
\end{abstract}

Kata kunci: aktivitas bongkar, kapal bouke ami, keselamatan kerja

\begin{abstract}
One of the scopes of occupational safety in fishermen is on the activity of loading catches. The loading activity is a process of decreasing the catch to the pier to the Fish auction site. Unloading activities have the most potential of workplace accidents because the activities involve many people in their activities and there are consequences of hazards that are categorized in great danger. The purpose of this research is to identify unloading activity of bouke ami in PPN Muara Angke, calculating the risk level of unloading activity of bouke ami crews, and provide recommendations for the safety of the crews work on unloading activities are more secure. The methods in this study are observations and interviews with fishermen and the crews regarding the activity of unloading activities and potential hazards. The analysis used is descriptive, Hierarchical Task Analysis, and Job Safety Analysis method. The results showed that there were 42 activities on the disassembly activities. Analysis of the HTA and JSA shows from 42 there are 10 (18.18\%) light categories, 29 (52.73\%) activities that included in intermediate category, 9 (16.36\%) activities that include in heavy category, and 7 (12.73\%) Activities
\end{abstract}


that include in fatal categories. Several activities have more than one category. The implementation of risk control can lower risk levels to lower categories. It is necessary to note that the completeness of life vest facilities, especially in the preparation of operations and the required transport driver of the catch that is certified to prevent a certified accident to prevent a fatal accident.

Key words: bouke ami vessel, occupational safety, unloading activity

\section{PENDAHULUAN}

Keselamatan kerja merupakan suatu upaya yang menjamin keutuhan dan keselamatan pekerja serta lingkungan (Bangun dan Haryono 2019). Keselamatan kerja perlu ditingkatkan tidak hanya di darat, namun juga diperlukan di sektor maritim, maka penambahan tanggung jawab perlu dilakukan oleh industri pelayaran dan pelabuhan khususnya bagi nelayan (Bangun dan Hariyono 2019). Lingkup pekerjaan nelayan salah satunya meliputi pekerjaan bongkar hasil tangkapan. Aktivitas bongkar merupakan proses penurunan hasil tangkapan ke dermaga (Gunawan et al. 2008). Setiap permasalahan yang terjadi dalam aktivitas ini berpotensi meningkatkan kecelakaan kerja sehingga kemungkinan dapat menimbulkan kerugian bagi pemilik kapal, maupun ABK yang sedang bekerja, seluruh risiko yang timbul mengakibatkan kerugian waktu dan biaya (Basuki et al. 2015).

Menurut Lestari et al. (2017), kegiatan yang memiliki potensi kecelakaan kerja paling tinggi ialah kegiatan operasi bongkar, karena pada kegiatan tersebut banyak melibatkan orang dalam aktivitasnya serta terdapat konsekuensi bahaya yang dikategorikan dalam bahaya besar. Potensi kecelakaan yang lebih besar pada kegiatan bongkar dari pada kegiatan muat, ini memerlukan adanya pencegahan atau solusi untuk mengurangi angka kecelakaan pada kegiatan operasi bongkar (Lestari et al. 2017).

Salah satu pelabuhan perikanan yang terdapat di Jakarta yaitu Pelabuhan Perikanan Nusantara (PPN) Muara Angke. Berdasarkan penelitian pendahuluan, rata-rata tahun 2019 kapal perikanan yang mendominasi di pelabuhan ini yaitu kapal cumi atau bouke ami. Aktivitas bongkar yang dilakukan pada kapal bouke ami melibatkan banyak ABK, sehingga terdapat potensi kecelakaan kerja bila tidak dilakukan secara hati-hati. Permasalahan yang teramati dari penelitian pendahuluan adalah ABK bouke ami secara umum belum memerhatikan aspek keselamatan kerja pada aktivitas bongkar.

Oleh karena itu pada penelitian ini akan ditelaah keselamatan kerja ABK bouke ami dengan cara mendapatkan rincian detil tahap-tahap pekerjaan yang dilakukan pada aktivitas bongkar, menganalisis risikonya, dan memberikan rekomendasi agar keselamatan kerja pada aktivitas bongkar dapat lebih terjamin. Kegiatan bongkar dilakukan di dermaga hingga menuju tempat penimbangan dan pelelangan. Hasil penelitian ini akan berkontribusi untuk nelayan setempat agar lebih memerhatikan keselamatan diri, dan untuk pemilik kapal dalam hal melengkapi awak kapalnya dengan alat pelindung diri saat bekerja di kapal.

Tujuan penelitian ini adalah mengidentifikasi aktivitas bongkar kapal bouke ami di PPN Muara Angke, menghitung tingkat risiko aktivitas bongkar anak buah kapal bouke ami, dan memberikan rekomendasi agar keselamatan kerja ABK pada aktivitas bongkar lebih terjamin.

\section{METODE PENELITIAN}

Penelitian dilaksanakan di Pelabuhan Perikanan Nusantara Muara Angke yang terletak di Kelurahan Kapuk Muara, Kecamatan Penjaringan, Kota Administrasi Jakarta Utara pada Januari 2020. Data dikumpulkan dengan metode observasi langsung dan wawancara kepada ABK bongkar di Pelabuhan Perikanan Muara Angke. Observasi langsung merupakan keterlibatan secara langsung oleh peneliti (Purnomo 2011). Survei merupakan pemeriksaan secara komprehensif, biasanya dalam penelitian dilakukan dengan menyebarkan kuesioner atau wawancara, dengan tujuan untuk 
mengetahui siapa mereka, apa yang mereka pikir, rasakan, atau kecenderungan suatu tindakan (Muflihin 2019).

Pengambilan sampel dilakukan menggunakan metode accidental sampling. Menurut Sugiyono (1997) yang dikutip dalam jurnal Parubak (2010) metode accidental sampling adalah metode pengambilan sampel yang dilakukan berdasarkan kebetulan. Penggunaan metode ini dipilih karena populasi nelayan dan kapal bouke ami di PPN Muara Angke mencapai 9383 orang dan 831 kapal. Proses kerja pada aktivitas bongkar di semua kapal tersebut sama, sehingga pada penelitian ini dilakukan pengamatan terhadap kapal yang sedang melakukan aktivitas bongkar di dermaga pelabuhan. Oleh karena itu metode accidental sampling diterapkan pada penelitian ini.

\section{HASIL DAN PEMBAHASAN}

\section{Kegiatan Bongkar Kapal Bouke Ami}

Kapal bouke ami yang akan melalukan proses bongkar masuk ke dermaga untuk menyiapkan proses pembongkaran. Dengan memosisikan kapal agar tepat di pinggir dermaga yang diatur oleh kapten dan KKM bertugas memosisikan kapal dan ABK mengaitkan tali pengait dan jangkar agar kapal dapat berdiam jika terkena gelombang air laut. Kemudian yang lainnya bertugas menyiapkan peralatan yang dibutuhkan dalam proses pembongkaran seperti keranjang angkut, alat timbangan, gerobak, dll. Kegiatan bongkar pada kapal bouke ami dibagi menjadi tiga tahapan, dapat dilihat pada Tabel 1.

Tabel 1 Tahapan Aktivitas Bongkar Kapal Bouke Ami

\begin{tabular}{cl}
\hline No & \multicolumn{1}{c}{ Tahapan Aktivitas } \\
\hline 1 & Persiapan Operasi Bongkar \\
2 & Operasi Bongkar \\
3 & Pasca Operasi Bongkar \\
\hline
\end{tabular}

Setiap tahapan aktivitas bongkar kapal bouke ami akan dijelaskan lebih lanjut menjadi beberapa sub aktivitas. Disertakan pula penanggung jawab, alat yang digunakan, dan jumlah orang yang bekerja. Sehingga tidak jarang adanya potensi kecelakaan yang terjadi.

\section{Aktivitas persiapan operasi bongkar}

Aktivitas persiapan operasi bongkar dilakukan ketika kapal mulai sampai di dermaga dan berlabuh. Para pelaku pada aktivitas ini dilakukan oleh kapten, KKM, buruh angkut, juru timbang, dan ABK. Alat yang digunakan yaitu tali dan jangkar, keranjang, gerobak angkut. Berikut aktivitas persiapan operasi bongkar disajikan pada Tabel 2 .

Tabel 2 Aktivitas Persiapan Operasi Bongkar

\begin{tabular}{|c|c|c|c|c|}
\hline No & Aktivitas & Pelaku & $\begin{array}{c}\text { Jumlah } \\
\text { Orang }\end{array}$ & Alat yang digunakan \\
\hline \multirow[t]{5}{*}{1} & Kapal Bouke Ami berlabuh di dermaga & Kapten & & \multirow{5}{*}{ Tali dan jangkar } \\
\hline & 1.1 Memosisikan kapal di dermaga & KKM & 1 & \\
\hline & 1.2 Melempar tali penahan ke dermaga & ABK & 1 & \\
\hline & $\begin{array}{l}\text { 1.3 Mengikatkan tali penahan ke } \\
\text { dermaga }\end{array}$ & ABK & 2 & \\
\hline & 1.4 Mematikan mesin kapal & KKM & 1 & \\
\hline \multirow[t]{2}{*}{2} & Kapten dan ABK turun dari kapal & & & \\
\hline & $\begin{array}{l}\text { 2.1 Melompat langsung dari kapal ke } \\
\text { dermaga }\end{array}$ & ABK & $4-5$ & \\
\hline
\end{tabular}




\begin{tabular}{|c|c|c|c|c|}
\hline No & Aktivitas & Pelaku & $\begin{array}{c}\text { Jumlah } \\
\text { Orang }\end{array}$ & Alat yang digunakan \\
\hline \multirow[t]{4}{*}{3} & Penyiapan keranjang angkut & $\begin{array}{l}\text { Buruh } \\
\text { angkut }\end{array}$ & $5-6$ & Keranjang \\
\hline & $\begin{array}{l}\text { 3.1 Memindahkan tumpukan keranjang } \\
\text { angkut dari TPI ke dermaga }\end{array}$ & $\begin{array}{l}\text { Buruh } \\
\text { angkut }\end{array}$ & $5-6$ & Keranjang \\
\hline & $\begin{array}{l}\text { 3.2 Menumpuk keranjang biru di } \\
\text { dermaga }\end{array}$ & $\begin{array}{l}\text { Buruh } \\
\text { angkut }\end{array}$ & $5-6$ & Keranjang \\
\hline & $\begin{array}{l}\text { 3.3 Menumpuk keranjang kuning di } \\
\text { dermaga }\end{array}$ & $\begin{array}{l}\text { Buruh } \\
\text { angkut }\end{array}$ & $5-6$ & Keranjang \\
\hline \multirow[t]{3}{*}{4} & Penyiapan penimbangan hasil tangkapan & $\begin{array}{l}\text { Juru } \\
\text { timbang }\end{array}$ & 6 & $\begin{array}{l}\text { Timbangan dan } \\
\text { keranjang }\end{array}$ \\
\hline & $\begin{array}{l}\text { 4.1 Memindahkan alat timbangan dari } \\
\text { TPI ke dermaga }\end{array}$ & $\begin{array}{l}\text { Buruh } \\
\text { angkut }\end{array}$ & 5 & Timbangan \\
\hline & $\begin{array}{l}\text { 4.2 Membawa gerobak angkut dari TPI } \\
\text { ke dermaga }\end{array}$ & $\begin{array}{l}\text { Buruh } \\
\text { angkut }\end{array}$ & 5 & Gerobak angkut \\
\hline
\end{tabular}

Kelancaran, kecepatan, pencapaian kinerja, dan keselamatan dalam melaksanakan kegiatan bongkar merupakan akumulasi kerja dari banyak pihak yang berkepentingan (Krisnawati et al. 2019). Karena itu dalam pelaksanaan bongkar merupakan kinerja yang bersifat sinergis dari tenaga kerja bongkar, ABK dan buruh angkut. Penggunaan alat-alat kerja yang sederhana dan terlihat tidak berbahaya, tetapi tetap saja terdapat risiko kecelakaan. Kebutuhan rasa aman akan muncul setelah kebutuhan fisik dan biologis terpenuhi, sehingga keselamatan kerja menjadi usaha yang harus diprioritaskan (Asriani 2016).

\section{Aktivitas operasi bongkar}

Aktivitas operasi bongkar dilakukan ketika kapal sudah siap untuk dibongkar dan peralatan yang dibutuhkan juga sudah siap di dermaga. Penanggung jawab pada aktivitas bongkar dilakukan oleh kapten, juru timbang, buruh angkut, dan buruh angkut industri. Peralatan yang digunakan yaitu keranjang, timbangan, gerobak angkut, dan mobil kontainer berpendingin. Berikut aktivitas bongkar disajikan pada Tabel 3.

Tabel 3 Aktivitas Operasi Bongkar

\begin{tabular}{|c|c|c|c|c|}
\hline No & Aktivitas & Pelaku & $\begin{array}{c}\text { Jumlah } \\
\text { Orang }\end{array}$ & Alat yang digunakan \\
\hline \multirow[t]{4}{*}{1} & $\begin{array}{l}\text { Pengeluaran hasil tangkapan sampingan } \\
\text { dari palka }\end{array}$ & Kapten & & \\
\hline & 1.1 Membuka palka ikan & ABK & 3 & \\
\hline & 1.2 Satu orang turun ke palka & $\mathrm{ABK}$ & 1 & \\
\hline & $\begin{array}{l}1.3 \text { Mengeluarkan hasil tangkapan } \\
\text { sampingan dari palka }\end{array}$ & $\mathrm{ABK}$ & $3-4$ & \\
\hline \multirow[t]{2}{*}{2} & $\begin{array}{l}\text { Hasil tangkapan dimasukkan ke } \\
\text { keranjang }\end{array}$ & Kapten & $4-7$ & \\
\hline & $\begin{array}{l}\text { 2.1 Hasil tangkapan sampingan dilempar } \\
\text { ke keranjang angkut }\end{array}$ & ABK & 4 & Keranjang \\
\hline \multirow[t]{2}{*}{3} & Hasil tangkapan ditimbang & $\begin{array}{l}\text { Juru } \\
\text { timbang }\end{array}$ & $4-6$ & $\begin{array}{l}\text { Keranjang dan } \\
\text { timbangan }\end{array}$ \\
\hline & $\begin{array}{l}\text { 3.1 } \begin{array}{l}\text { Mengangkat hasil tangkapan } \\
\text { sampingan ke alat penimbang }\end{array}\end{array}$ & $\begin{array}{l}\text { Buruh } \\
\text { angkut }\end{array}$ & $3-4$ & $\begin{array}{l}\text { Keranjang dan } \\
\text { timbangan }\end{array}$ \\
\hline
\end{tabular}




\begin{tabular}{|c|c|c|c|c|c|}
\hline \multirow[t]{2}{*}{ No } & \multicolumn{2}{|r|}{ Aktivitas } & \multirow{2}{*}{$\begin{array}{l}\text { Pelaku } \\
\text { Juru } \\
\text { timbang }\end{array}$} & \multirow{2}{*}{$\begin{array}{c}\begin{array}{c}\text { Jumlah } \\
\text { Orang }\end{array} \\
4-5\end{array}$} & \multirow{2}{*}{$\begin{array}{l}\text { Alat yang digunakan } \\
\text { Keranjang dan } \\
\text { timbangan }\end{array}$} \\
\hline & 3.2 & $\begin{array}{l}\text { Menimbang hasil tangkapan } \\
\text { sampingan }\end{array}$ & & & \\
\hline \multirow[t]{3}{*}{4} & Hasi & il tangkapan dibawa ke TPI & $\begin{array}{l}\text { Buruh } \\
\text { angkut }\end{array}$ & & $\begin{array}{l}\text { Gerobak angkut dan } \\
\text { keranjang }\end{array}$ \\
\hline & 4.1 & $\begin{array}{l}\text { Memindahkan hasil tangkapan } \\
\text { sampingan ke gerobak angkut }\end{array}$ & $\begin{array}{l}\text { Buruh } \\
\text { angkut }\end{array}$ & 3 & $\begin{array}{l}\text { Keranjang dan } \\
\text { gerobak angkut }\end{array}$ \\
\hline & 4.2 & $\begin{array}{l}\text { Hasil tangkapan sampingan } \\
\text { dipindahkan ke TPI }\end{array}$ & $\begin{array}{l}\text { Buruh } \\
\text { angkut }\end{array}$ & 6 & $\begin{array}{l}\text { Gerobak angkut dan } \\
\text { keranjang }\end{array}$ \\
\hline \multirow[t]{3}{*}{5} & Peng & geluaran hasil tangkapan utama & Kapten & & \\
\hline & 5.1 & $\begin{array}{l}\text { Mengeluarkan hasil tangkapan } \\
\text { utama berupa cumi dari palka }\end{array}$ & $\mathrm{ABK}$ & $3-4$ & \\
\hline & 5.2 & $\begin{array}{l}\text { Hasil tangkapan utama } \\
\text { dipindahkan ke keranjang angkut }\end{array}$ & $\begin{array}{l}\text { Buruh } \\
\text { angkut }\end{array}$ & $4-5$ & Keranjang angkut \\
\hline \multirow[t]{3}{*}{6} & Pen & imbangan hasil tangkapan utama & $\begin{array}{l}\text { Juru } \\
\text { timbang }\end{array}$ & $4-6$ & $\begin{array}{l}\text { Alat penimbang dan } \\
\text { keranjang }\end{array}$ \\
\hline & 6.1 & $\begin{array}{l}\text { Mengangkat hasil tangkapan } \\
\text { utama ke alat penimbang }\end{array}$ & $\begin{array}{l}\text { Buruh } \\
\text { angkut }\end{array}$ & $3-4$ & Keranjang \\
\hline & 6.2 & Hasil tangkapan utama ditimbang & $\begin{array}{l}\text { Juru } \\
\text { timbang }\end{array}$ & $4-5$ & $\begin{array}{l}\text { Alat penimbang dan } \\
\text { keranjang }\end{array}$ \\
\hline \multirow[t]{8}{*}{7} & $\begin{array}{l}\text { Hasi } \\
\text { indu }\end{array}$ & $\begin{array}{l}\text { il tangkapan utama dibawa ke } \\
\text { stri }\end{array}$ & $\begin{array}{l}\text { Buruh } \\
\text { angkut } \\
\text { industri }\end{array}$ & $3-4$ & $\begin{array}{l}\text { Keranjang dan mobil } \\
\text { kontainer } \\
\text { berpendingin }\end{array}$ \\
\hline & 7.1 & $\begin{array}{l}\text { Kedatangan mobil kontainer } \\
\text { berpendingin ke dermaga }\end{array}$ & $\begin{array}{l}\text { Sopir mobil } \\
\text { kontainer }\end{array}$ & 4 & \\
\hline & 7.2 & $\begin{array}{l}\text { Memosisikan mobil kontainer } \\
\text { berpendingin di dermaga }\end{array}$ & $\begin{array}{l}\text { Sopir mobil } \\
\text { kontainer }\end{array}$ & 2 & \\
\hline & 7.3 & $\begin{array}{l}\text { Membuka pintu kontainer } \\
\text { berpendingin }\end{array}$ & $\begin{array}{l}\text { Buruh } \\
\text { angkut } \\
\text { industri }\end{array}$ & 1 & \\
\hline & 7.4 & $\begin{array}{l}\text { Mengangkat hasil tangkapan utama } \\
\text { ke mobil kontainer berpendingin }\end{array}$ & $\begin{array}{l}\text { Buruh } \\
\text { angkut }\end{array}$ & 2 & \\
\hline & 7.4 & $\begin{array}{l}\text { Menata hasil tangkapan utama di } \\
\text { dalam mobil kontainer } \\
\text { berpendingin }\end{array}$ & $\begin{array}{l}\text { industri } \\
\text { Buruh } \\
\text { angkut }\end{array}$ & 1 & \\
\hline & 7.5 & $\begin{array}{l}\text { Jika kapasitas sudah penuh pintu } \\
\text { kontainer berpendingin di tutup }\end{array}$ & $\begin{array}{l}\text { industri } \\
\text { Buruh }\end{array}$ & 1 & \\
\hline & 7.6 & $\begin{array}{l}\text { Mobil kontainer berpendingin } \\
\text { berangkat ke tempat industri }\end{array}$ & $\begin{array}{l}\text { angkut } \\
\text { industri } \\
\text { Sopir mobil } \\
\text { kontainer }\end{array}$ & $3-4$ & \\
\hline
\end{tabular}

Para pekerja yang melakukan bongkar, tidak menggunakan APD (Alat Pelindung Diri) yang lengkap guna mencegah terjadinya kecelakaan kerja. APD merupakan suatu alat yang melindungi seseorang dan mengisolasi sebagian atau seluruh tubuh dari potensi bahaya di tempat kerja (Hadi 2018).

\section{Aktivitas pasca operasi bongkar}

Aktivitas pasca operasi bongkar dilakukan ketika proses pembongkaran seluruh hasil tangkapan selesai. Orang yang bertanggung jawab pada pasca operasi bongkar yaitu kapten dan buruh angkut. 
Alat-alat yang digunakan yaitu ember, keranjang, alat penimbang, gerobak angkut, tali dan jangkar. Berikut aktivitas pasca bongkar disajikan pada Tabel 4.

Tabel 4 Aktivitas Pasca Operasi Bongkar

\begin{tabular}{|c|c|c|c|c|}
\hline No & Aktivitas & Pelaku & $\begin{array}{l}\text { Jumlah } \\
\text { Orang }\end{array}$ & $\begin{array}{l}\text { Alat yang } \\
\text { digunakan }\end{array}$ \\
\hline \multirow[t]{5}{*}{1} & Pembersihan kapal pasca bongkar & Kapten & & \\
\hline & 1.1 Mengambil air laut & $\mathrm{ABK}$ & $3-4$ & \\
\hline & 1.2 Menyiram dek kapal dengan air laut & $\mathrm{ABK}$ & $2-3$ & Ember \\
\hline & 1.3 Menyiram palka dengan air laut & ABK & $2-3$ & Ember \\
\hline & 1.4 Menutup pintu palka & $\mathrm{ABK}$ & 2 & Ember \\
\hline \multirow[t]{5}{*}{2} & Membereskan peralatan bongkar & Buruh angkut & $5-6$ & \\
\hline & $\begin{array}{l}\text { 2.1 Memindahkan keranjang kuning ke } \\
\text { TPI }\end{array}$ & Buruh angkut & $5-6$ & \\
\hline & 2.2 Memindahkan keranjang biru ke TPI & Buruh angkut & $5-6$ & Keranjang \\
\hline & 2.3 Memindahkan alat penimbang ke TPI & Buruh angkut & 5 & Keranjang \\
\hline & 2.4 Memindahkan gerobak angkut ke TPI & Buruh angkut & 5 & $\begin{array}{l}\text { Alat timbangan } \\
\text { Gerobak }\end{array}$ \\
\hline \multirow[t]{6}{*}{3} & Kapal Bouke Ami meninggalkan dermaga & Kapten & & \\
\hline & 3.1 Menyalakan mesin kapal & KKM & 1 & \\
\hline & $\begin{array}{l}\text { 3.2 Melepaskan tali penahan dari ikatan } \\
\text { di dermaga }\end{array}$ & ABK & 2 & Tali dan jangkar \\
\hline & 3.3 Mengangkat tali penahan ke kapal & ABK & 2 & \\
\hline & $\begin{array}{l}\text { Memosisikan kapal keluar dari } \\
\text { dermaga }\end{array}$ & KKM & 3 & Tali dan jangkar \\
\hline & 3.5 Kapal meninggalkan dermaga & & & \\
\hline
\end{tabular}

Potensi Bahaya Kegiatan Bongkar Kapal Bouke Ami

Kegiatan bongkar kapal Bouke Ami di Pelabuhan Perikanan Nusantara Muara Angke memiliki potensi kecelakaan kerja selama proses pembongkaran berlangsung. Aktivitas bongkar ini dilakukan mulai pukul 05.45 WIB jika tidak ada gangguan cuaca seperti hujan. Proses bongkar tiap kapalnya berlangsung sekitar kurang lebih dua jam. Namun, jika pagi hari mulai turun hujan, aktivitas bongkar ditunda sampai hujan reda karena kualitas ikan akan turun atau daging ikan akan lembek jika tidak ditangani dengan segera, karena ketika turun hujan, pergerakan ABK tidak segesit saat tidak hujan dan potensi kecelakaan bisa bertambah.

Kecelakaan kerja berpotensi pada orang-orang yang terlibat dalam aktivitas bongkar seperti kapten, juru timbang, buruh angkut, buruh angkut industri dan lain-lain. Selain itu terdapat juga faktor-faktor yang berpengaruh pada kecelakaan kerja secara sistematis yaitu faktor lingkungan kerja, faktor pekerjaan, dan faktor manusia. Terdapat juga faktor karakteristik pekerja seperti kurang kemampuan/pelatihan, menerima pekerja yang tidak tepat, kelelahan akibat jam kerja yang berlebihan, serta minimnya pengawasan terhadap pekerja (Fahdilah et al. 2013). Pada saat melakukan aktivitas bongkar, potensi kecelakaan yang dapat terjadi misalnya jatuh tergelincir akibat lantai dek yang licin dan ABK yang tidak mengenakan APD berupa sepatu karet, tertimpa cumi beku, rusaknya hasil tangkapan, dan masih banyak lagi. Kecelakaan disebut juga kejadian yang tidak diharapkan dan tidak terduga, karena tidak terdapat unsur kesengajaan, kecelakaan dapat terjadi karena oleh pekerjaan atau pada waktu melaksanakan pekerjaan (Aryantiningsih 2015).

\section{Tahapan persiapan operasi bongkar}

Pada tahap persiapan operasi bongkar dimulai dari kapal berlabuh lalu KKM memosisikan kapal di dermaga dan yang lainnya mempersiapkan aktivitas pembongkaran hasil tangkapan kapal bouke ami 
di PPN Muara Angke. Tahapan ini terbentuk menjadi 4 aktivitas dan masing-masing dijelaskan lebih rinci pada sub aktivitas. Berikut merupakan rincian kegagalan pada tahap persiapan operasi bongkar ditunjukkan pada Tabel 5.

Tabel 5 Identifikasi Kegagalan pada Tahap Persiapan Operasi Bongkar

\begin{tabular}{|c|c|c|c|}
\hline Langkah & Aktivitas & Potensi Bahaya & $\begin{array}{c}\text { Konsekuensi } \\
\text { Bahaya }\end{array}$ \\
\hline 1 & \multicolumn{3}{|c|}{ Kapal bouke ami berlabuh di dermaga } \\
\hline 1.1 & $\begin{array}{l}\text { Memosisikan kapal di } \\
\text { dermaga }\end{array}$ & $\begin{array}{l}\text { Menabrak kapal lain, salah arah, } \\
\text { menabrak dinding dermaga }\end{array}$ & Menengah \\
\hline 1.2 & $\begin{array}{l}\text { Melemparkan tali } \\
\text { penahan ke dermaga }\end{array}$ & $\begin{array}{l}\text { Tali penahan jatuh ke air, tali penahan } \\
\text { kusut dan terlilit, ABK jatuh ke air }\end{array}$ & Berat \\
\hline 1.3 & $\begin{array}{l}\text { Mengikatkan tali penahan } \\
\text { ke dermaga }\end{array}$ & $\begin{array}{l}\text { Tali penahan kusut dan terlilit, tali } \\
\text { masih longgar, kapal tidak bisa berdiam } \\
\text { di dermaga }\end{array}$ & Menengah \\
\hline 1.4 & Mematikan mesin kapal & $\begin{array}{l}\text { Mesin tidak bisa mati sehingga bahan } \\
\text { bakar terus terpakai, boros }\end{array}$ & Ringan \\
\hline 2 & \multicolumn{3}{|c|}{ Kapten dan ABK turun dari kapal } \\
\hline 2.1 & $\begin{array}{l}\text { Melompat langsung dari } \\
\text { kapal ke dermaga }\end{array}$ & Terpeleset, jatuh ke air & Berat \\
\hline 3 & \multicolumn{3}{|l|}{ Penyiapan keranjang angkut } \\
\hline 3.1 & $\begin{array}{l}\text { Memindahkan tumpukan } \\
\text { keranjang angkut dari TPI } \\
\text { ke dermaga }\end{array}$ & $\begin{array}{l}\text { Jumlah keranjang tidak memadai, } \\
\text { terpeleset, tumpukan keranjang } \\
\text { berantakan, keranjang rusak }\end{array}$ & Menengah \\
\hline 3.2 & $\begin{array}{l}\text { Menumpuk keranjang } \\
\text { biru di dermaga }\end{array}$ & $\begin{array}{l}\text { Jatuh terpeleset, tumpukan keranjang } \\
\text { jatuh, keranjang pecah }\end{array}$ & Menengah \\
\hline 3.3 & $\begin{array}{l}\text { Menumpuk keranjang } \\
\text { kuning di dermaga }\end{array}$ & $\begin{array}{l}\text { Jatuh terpeleset, tumpukan keranjang } \\
\text { jatuh, keranjang pecah }\end{array}$ & Menengah \\
\hline 4 & \multicolumn{3}{|c|}{ Penyiapan penimbangan hasil tangkapan } \\
\hline 4.1 & $\begin{array}{l}\text { Memindahkan alat } \\
\text { timbangan dari TPI ke } \\
\text { dermaga }\end{array}$ & $\begin{array}{l}\text { Jatuh, alat timbangan tidak ada, alat } \\
\text { timbangan rusak }\end{array}$ & Ringan \\
\hline 4.2 & $\begin{array}{l}\text { Membawa gerobak } \\
\text { angkut dari TPI ke } \\
\text { dermaga }\end{array}$ & $\begin{array}{l}\text { Gerobak angkut rusak, terjatuh, } \\
\text { gerobak angkut tidak ada }\end{array}$ & Ringan \\
\hline
\end{tabular}

Dari tabel tahapan aktivitas persiapan operasi bongkar, terdapat 10 sub aktivitas, 3 (30\%) aktivitas yang masuk dalam kategori bahaya ringan yang mana sesuai dengan tabel skala probability yaitu jarang terjadi, 5 (50\%) masuk dalam kategori bahaya menengah dengan skala probability yaitu dapat terjadi kadang-kadang, dan $2(20 \%)$ masuk dalam kategori bahaya berat dengan skala probability yaitu jarang terjadi. Suatu tahap dikatakan bahaya ringan apabila terdapat luka ringan dan membutuhkan penanganan langsung tanpa membutuhkan peralatan medis yang serius. Suatu tahap masuk ke dalam bahaya menengah apabila cedera ringan, membutuhkan penanganan medis dokter/rumah sakit, membutuhkan waktu penyembuhan, dan suatu tahap masuk kategori bahaya berat apabila cedera berat/serius, mengakibatkan cacat, membutuhkan waktu penyembuhan hingga tidak masuk kerja.

\section{Tahapan operasi bongkar}

Pada tahap ini kegiatan dimulai saat palka dibuka dan hasil tangkapan mulai dikeluarkan, dimulai dari mengeluarkan hasil tangkapan sampingan hingga ke hasil tangkapan utama. Kemudian hasil tangkapan dipindahkan ke dermaga untuk dimasukkan ke dalam keranjang, lalu ditimbang, dan 
diangkat ke gerobak angkut untuk dibawa ke TPI. Berikut merupakan rincian identifikasi kegagalan pada tahap operasi bongkar ditunjukkan pada Tabel 6 .

Tabel 6 Identifikasi Kegagalan pada Tahap Operasi Bongkar

\begin{tabular}{|c|c|c|c|}
\hline Langkah & Aktivitas & Potensi Bahaya & $\begin{array}{c}\text { Konsekuensi } \\
\text { Bahaya }\end{array}$ \\
\hline 1 & \multicolumn{3}{|c|}{ Pengeluaran hasil tangkapan sampingan dari palka } \\
\hline 1.1 & Membuka palka ikan & Pintu palka susah terbuka & Ringan \\
\hline 1.2 & $\begin{array}{l}\text { Satu orang } A B K \text { turun ke } \\
\text { palka }\end{array}$ & $\begin{array}{l}\text { Jatuh terpeleset, jatuh menimpa hasil } \\
\text { tangkapan }\end{array}$ & Menengah \\
\hline 1.3 & $\begin{array}{l}\text { Mengeluarkan hasil } \\
\text { tangkapan sampingan dari } \\
\text { palka }\end{array}$ & $\begin{array}{l}\text { Jatuh, terpeleset, hasil tangkapan } \\
\text { menimpa kaki }\end{array}$ & Menengah \\
\hline 2 & \multicolumn{3}{|c|}{ Hasil tangkapan dimasukan ke keranjang } \\
\hline 2.1 & $\begin{array}{l}\text { Hasil tangkapan } \\
\text { sampingan dilempar ke } \\
\text { keranjang angkut }\end{array}$ & $\begin{array}{l}\text { Hasil tangkapan rusak, keranjang } \\
\text { pecah, hasil tangkapan terjatuh } \\
\text { menimpa kaki }\end{array}$ & Menengah \\
\hline 3 & & \\
\hline 3.1 & $\begin{array}{l}\text { Mengangkat hasil } \\
\text { tangkapan sampingan ke } \\
\text { alat penimbang }\end{array}$ & $\begin{array}{l}\text { Jika kelebihan muatan hasil tangkapan } \\
\text { bisa terjatuh, keranjang bisa rusak, alat } \\
\text { penimbang bisa rusak, hasil tangkapan } \\
\text { jatuh mengenai kaki }\end{array}$ & Menengah \\
\hline 3.2 & $\begin{array}{l}\text { Menimbang hasil } \\
\text { tangkapan sampingan }\end{array}$ & Timbangan tidak akurat & Ringan \\
\hline 4 & \multicolumn{2}{|c|}{ Hasil tangkapan dibawa ke TPI } & \\
\hline 4.1 & $\begin{array}{l}\text { Memindahkan hasil } \\
\text { tangkapan sampingan ke } \\
\text { gerobak angkut }\end{array}$ & $\begin{array}{l}\text { Jika kelebihan muatan hasil tangkapan } \\
\text { bisa terjatuh, keranjang bisa rusak, } \\
\text { gerobak angkut bisa terjatuh, hasil } \\
\text { tangkapan jatuh mengenai kaki }\end{array}$ & Menegah \\
\hline 4.2 & $\begin{array}{l}\text { Hasil tangkapan } \\
\text { sampingan dipindahkan } \\
\text { ke TPI }\end{array}$ & $\begin{array}{l}\text { Jika kelebihan muatan hasil tangkapan } \\
\text { bisa terjatuh, keranjang bisa rusak, } \\
\text { gerobak angkut bisa terjatuh, hasil } \\
\text { tangkapan jatuh mengenai kaki }\end{array}$ & Menengah \\
\hline 5 & \multicolumn{2}{|c|}{ Pengeluaran hasil tangkapan utama } & \\
\hline 5.1 & $\begin{array}{l}\text { Mengeluarkan hasil } \\
\text { tangkapan utama berupa } \\
\text { cumi dari palka }\end{array}$ & $\begin{array}{l}\text { Jatuh, terpeleset, hasil tangkapan } \\
\text { menimpa kaki, hasil tangkapan rusak }\end{array}$ & Menengah \\
\hline 5.2 & $\begin{array}{l}\text { Hasil tangkapan utama } \\
\text { dipindahkan ke keranjang } \\
\text { angkut }\end{array}$ & $\begin{array}{l}\text { Hasil tangkapan terjatuh menimpa } \\
\text { kaki, hasil tangkapan rusak, }\end{array}$ & Menengah \\
\hline 6 & \multicolumn{2}{|c|}{ Penimbangan hasil tangkapan utama } & \\
\hline 6.1 & $\begin{array}{l}\text { Mengangkat hasil } \\
\text { tangkapan utama ke alat } \\
\text { penimbang }\end{array}$ & $\begin{array}{l}\text { Jika kelebihan muatan hasil tangkapan } \\
\text { bisa terjatuh, keranjang bisa rusak, alat } \\
\text { penimbang bisa rusak, hasil tangkapan } \\
\text { jatuh mengenai kaki }\end{array}$ & Menengah \\
\hline 6.2 & $\begin{array}{l}\text { Hasil tangkapan utama } \\
\text { ditimbang }\end{array}$ & Alat timbangan tidak akurat & Ringan \\
\hline
\end{tabular}




\begin{tabular}{|c|c|c|c|}
\hline Langkah & Aktivitas & Potensi Bahaya & $\begin{array}{c}\text { Konsekuensi } \\
\text { Bahaya }\end{array}$ \\
\hline 7 & \multicolumn{3}{|c|}{ Hasil tangkapan utama dibawa ke industri } \\
\hline 7.1 & $\begin{array}{l}\text { Kedatangan mobil } \\
\text { kontainer berpendingin } \\
\text { ke dermaga }\end{array}$ & $\begin{array}{l}\text { Mobil tidak sampai di dermaga, mobil } \\
\text { mengalami tabrakan di dermaga }\end{array}$ & $\begin{array}{l}\text { Menengah, } \\
\text { berat, fatal }\end{array}$ \\
\hline 7.2 & $\begin{array}{l}\text { Memosisikan mobil } \\
\text { kontainer berpendingin di } \\
\text { dermaga }\end{array}$ & Mobil mengalami tabrakan di dermaga & $\begin{array}{l}\text { Menengah, } \\
\text { berat, fatal }\end{array}$ \\
\hline 7.3 & $\begin{array}{l}\text { Membuka pintu mobil } \\
\text { kontainer berpendingin }\end{array}$ & Pintu kontainer sulit terbuka, & Ringan \\
\hline 7.4 & $\begin{array}{l}\text { Mengangkat hasil } \\
\text { tangkapan utama ke mobil } \\
\text { kontainer berpendingin }\end{array}$ & $\begin{array}{l}\text { Jatuh, terpeleset, hasil tangkapan jatuh } \\
\text { menimpa kaki, jika kelebihan muatan } \\
\text { keranjang pecah }\end{array}$ & Menengah \\
\hline 7.5 & $\begin{array}{l}\text { Menata hasil tangkapan } \\
\text { utama di dalam mobil } \\
\text { kontainer berpendingin }\end{array}$ & $\begin{array}{l}\text { Hasil tangkapan berantakan, alat } \\
\text { pendingin tidak berfungsi }\end{array}$ & Menengah \\
\hline 7.6 & $\begin{array}{l}\text { Jika kapasitas sudah } \\
\text { penuh pintu mobil } \\
\text { kontainer berpendingin } \\
\text { ditutup }\end{array}$ & Pintu sulit ditutup & Ringan \\
\hline 7.7 & $\begin{array}{l}\text { Mobil kontainer } \\
\text { berpendingin berangkat } \\
\text { ke tempat industri }\end{array}$ & $\begin{array}{l}\text { Mobil mengalami kecelakaan, alat } \\
\text { pendingin tidak berfungsi }\end{array}$ & Berat, fatal \\
\hline
\end{tabular}

Terdapat 19 sub aktivitas pada tabel tahapan aktivitas operasi bongkar, yaitu: 5 (20.8\%) aktivitas yang masuk dalam kategori bahaya ringan dengan skala probability yaitu jarang terjadi, 13 (54.2\%) masuk dalam kategori bahaya menengah dengan skala probability yaitu sering terjadi, 3 (12.5\%) masuk dalam kategori bahaya berat dengan skala probability yaitu sangat jarang terjadi, dan 3 (12.5\%) masuk dalam bahaya fatal dengan skala probability yaitu sangat jarang terjadi. Terdapat beberapa sub aktivitas yang memiliki lebih dari satu kategori.

\section{Tahapan pasca operasi bongkar}

Kegiatan pasca bongkar merupakan akhir dari kegiatan bongkar kapal. Pada tahap ini terdapat tiga aktivitas utama yang akan dijelaskan lebih rinci lagi pada tabel. Berikut merupakan tabel identifikasi kegagalan pada tahap pasca operasi bongkar yang akan dijelaskan pada Tabel 7.

Tabel 7 Identifikasi Kegagalan pada Tahap Pasca Operasi Bongkar

\begin{tabular}{|c|c|c|c|}
\hline Langkah & Aktivitas & Potensi Bahaya & $\begin{array}{c}\text { Konsekuensi } \\
\text { Bahaya }\end{array}$ \\
\hline 1 & \multicolumn{3}{|c|}{ Pembersihan kapal pasca bongkar } \\
\hline 1.1 & Mengambil air laut & Jatuh, terpeleset, jatuh ke laut & $\begin{array}{l}\text { Menengah, } \\
\text { berat, fatal }\end{array}$ \\
\hline 1.2 & $\begin{array}{l}\text { Menyiram dek kapal } \\
\text { dengan air laut }\end{array}$ & Jatuh, terpeleset & Menengah \\
\hline 1.3 & $\begin{array}{l}\text { Menyiram palka dengan } \\
\text { air laut }\end{array}$ & Jatuh, terpeleset & Menengah \\
\hline 1.4 & Menutup pintu palka & Jatuh, terpeleset & Menengah \\
\hline
\end{tabular}




\begin{tabular}{|c|c|c|c|}
\hline Langkah & Aktivitas & Potensi Bahaya & $\begin{array}{c}\text { Konsekuensi } \\
\text { Bahaya }\end{array}$ \\
\hline 2 & \multicolumn{3}{|c|}{ Membereskan peralatan bongkar } \\
\hline 2.1 & $\begin{array}{l}\text { Memindahkan keranjang } \\
\text { kuning ke TPI }\end{array}$ & $\begin{array}{l}\text { Jumlah keranjang tidak sesuai, } \\
\text { keranjang pecah, keranjang jatuh } \\
\text { berantakan }\end{array}$ & Menengah \\
\hline 2.2 & $\begin{array}{l}\text { Memindahkan keranjang } \\
\text { biru ke TPI }\end{array}$ & $\begin{array}{l}\text { Jumlah keranjang tidak sesuai, } \\
\text { keranjang pecah, keranjang jatuh } \\
\text { berantakan }\end{array}$ & Menengah \\
\hline 2.3 & $\begin{array}{l}\text { Memindahkan alat } \\
\text { penimbang ke TPI }\end{array}$ & Alat timbangan rusak, jatuh, terpeleset & Menengah \\
\hline 2.4 & $\begin{array}{l}\text { Memindahkan gerobak } \\
\text { angkut ke TPI }\end{array}$ & Jatuh, gerobak rusak, terpeleset & Menengah \\
\hline 3 & \multicolumn{3}{|c|}{ Kapal bouke ami meninggalkan dermaga } \\
\hline 3.1 & Menyalakan mesin kapal & Mesin tidak menyala & Ringan \\
\hline 3.2 & $\begin{array}{l}\text { Melepaskan tali penahan } \\
\text { dari ikatan di dermaga }\end{array}$ & $\begin{array}{l}\text { Tali susah lepas, tali kusut, kaki terlilit } \\
\text { tali, jatuh ke laut }\end{array}$ & $\begin{array}{l}\text { Menengah, } \\
\text { berat, fatal }\end{array}$ \\
\hline 3.3 & $\begin{array}{l}\text { Mengangkat tali penahan } \\
\text { ke kapal }\end{array}$ & $\begin{array}{l}\text { Tali kusut, kaki terlilit tali, jatuh ke } \\
\text { laut }\end{array}$ & $\begin{array}{l}\text { Menengah, } \\
\text { berat, fatal }\end{array}$ \\
\hline 3.4 & $\begin{array}{l}\text { Memosisikan kapal keluar } \\
\text { dari dermaga }\end{array}$ & $\begin{array}{l}\text { Kapal terbentur dinding dermaga, } \\
\text { kapal menabrak kapal lain, terjatuh ke } \\
\text { laut }\end{array}$ & $\begin{array}{l}\text { Menengah, } \\
\text { berat, fatal }\end{array}$ \\
\hline 3.5 & $\begin{array}{l}\text { Kapal meninggalkan } \\
\text { dermaga }\end{array}$ & Mesin kapal mati & Ringan \\
\hline
\end{tabular}

Penjelasan dari tabel tahap pasca operasi bongkar, terdapat 13 sub aktivitas, 2 (9.5\%) aktivitas yang masuk dalam kategori bahaya ringan dengan skala probability yaitu sangat jarang terjadi, 11 (52.5\%) masuk dalam kategori bahaya menengah dengan skala probability yaitu sangat sering terjadi, $4(19.05 \%)$ masuk dalam kategori bahaya berat dengan skala probability yaitu sangat jarang terjadi, dan $4(19.05) \%$ masuk dalam kategori bahaya fatal dengan skala probability yaitu sangat jarang terjadi. Terdapat satu sub aktivitas yang memiliki lebih dari satu kategori.

\section{KESIMPULAN DAN SARAN}

Aktivtas bongkar kapal bouke ami yang dilakukan di PPN Muara Angke terdiri dari 42 kegiatan yang dikelompokkan menjadi tiga bagian yaitu persiapan operasi bongkar, operasi bongkar, dan pasca operasi bongkar. Tingkat risiko aktivitas bongkar anak buah kapal bouke ami yang terdapat pada 42 kegiatan yaitu $10(18.18 \%)$ aktivitas yang termasuk kategori ringan, 29 (52.73\%) aktivitas yang termasuk kategori menengah, 9 (16.63\%) aktivitas yang termasuk kategori berat, dan 7 (12.73\%) aktivitas yang termasuk kategori fatal. Terdapat beberapa aktivitas yang mempunyai lebih dari satu kategori. Nelayan direkomendasikan agar mengenakan APD berupa life vest terutama pada persiapan operasi bongkar serta dibutuhkan pengemudi transportasi hasil tangkapan bersertifikat untuk mencegah kecelakaan yang bersifat fatal.

Pemilik kapal perlu menyediakan life vest untuk nelayan dan memodifikasi dek kapal guna mengurangi angka kecelakaan yang termasuk kategori menengah, serta diperlukannya pengemudi transportasi hasil tangkapan bersertifikasi dan kendaraan yang laik jalan. 


\section{DAFTAR PUSTAKA}

Asriani A. 2016. Keselamatan Kerja di Area Pelabuhan Perikanan Nusantara Palabuhanratu, Sukabumi, Jawa Barat. [Skripsi]. Institut Pertanian Bogor: ID

Bangun GAA dan Hariyono W. 2019. Analisis Penerapan Keselamatan dan Kesehatan Kerja (K3) pada Kapal Penumpang di PT PELNI Semarang. Seminar dan Konferensi Nasional IDEC. B09.1

Basuki M, Susanto RB, Herianto HP. 2015. Analisis Risiko Kegiatan Bongkar Muat sebagai Komponen Dwelling Time di Pelabuhan. Seminar Nasional Sains dan Teknologi Terapan III. 511-518

Fadhilah N, Suryanto, Ulfah N. 2013. Faktor-faktor yang memengaruhi kecelakaan kerja pada proses die casting di PT. X Cikarang Barat Kabupaten Bekasi Jawa Barat. Jurnal Kesmasindo. 6(2):135142.

Gunawan H, Suhartono, Sianto ME. 2008. Analisis Faktor-faktor yang Berpengaruh terhadap Produktivitas Bongkar Muat Kontainer di Dermaga Berlian Surabaya (Studi kasus PT Pelayaran Meratus). Widya Teknik. 7(1):78-89

Hadi MM. 2018. Perlidungan Hukum terhadap Keselamatan dan Kecelakaan Kerja bagi Tenaga Kerja Bongkar Muat (TKBM) Pelabuhan Lembar. [Skripsi]. Universitas Mataram: ID

Krisnawati S, Sugandi, Bijaksana G. 2019. Upaya Peningkatan Kinerja Tenaga Kerja Bongkar Muat di Pelabuhan Marunda Jakarta Utara. Jurnal Manajemen Bisnis Transportasi dan Logistik. 5(2): 268

Lestari DA, Purwangka F, Iskandar BH. 2017. Identifikasi Keselamatan Kerja Bongkar Muat Kapal Purse Seine di Muncar, Banyuwangi. Jurnal Teknologi dan Ilmu Perikanan. 13(1):31-37

Muflihin A. 2019. Survei Minat Siswa dalam Mengikuti Kegiatan Ekstrakulikuler Olahraga di SMA Negeri 3 Takalar. [Skripsi]. Universitas Negeri Makassar: ID

Parubak B. 2010. Faktor-faktor yang Dipertimbangkan Konsumen Dalam Pembelian Kain Donggala di Kotamadya Palu. Wacana. 13(4):4 